\title{
Theoretical dietary modelling of Australian seafood species to meet long-chain omega 3 fatty acid dietary recommendations
}

\author{
Jessica A. Grieger'*, Catherine McLeod ${ }^{2}$, Lily Chan' and \\ Michelle D. Miller'
}

'Nutrition and Dietetics, Flinders University, Adelaide, South Australia; ${ }^{2}$ South Australian Research and

Development Institute, Adelaide, South Australia

Abstract

Background: Several agencies recommend seafood to be consumed 2-3 times per week. In Australia, there is a lack of nutrient composition data for seafood species and it is not known whether including different seafood species in a diet would provide sufficient long-chain omega 3 fatty acids (LC $n-3$ PUFA) to meet various national recommendations.

Objective: To utilise recent nutrient composition data for major Australian seafood groups $(n=24)$ with the addition of two tuna options (total $n=26$ ) to: (1) determine whether including these species into a diet based on the Australian Guide to Healthy Eating (AGHE) will achieve LC $n-3$ PUFA recommendations [Adequate Intake (AI: $160 \mathrm{mg} / \mathrm{d}$ men, $90 \mathrm{mg} / \mathrm{d}$ women)], Suggested Dietary Target (SDT), $500 \mathrm{mg} / \mathrm{d}$ Heart Foundation (HF) recommendation and (2) determine the weekly number of servings of seafood to meet recommendations using either lower fat $(n=23,<10 \%$ total fat) or higher fat $(n=3, \geq 10 \%$ total fat) seafood.

Design: Two simulation models incorporated all 26 species of seafood or only lower fat seafood into a diet based on the AGHE. Two further models identified the number of servings of lower or higher fat seafood required to meet recommendations.

Results: Including 2 and 3 servings/week of any seafood would enable $89 \%$ of women and $66 \%$ of men to meet the AI. Including only lower fat seafood would enable $83 \%$ of women and $47 \%$ of men to meet the AI. Half a serving/week of higher fat seafood would enable $100 \%$ of men and women to meet the AI.

Conclusions: Including the recommended 2-3 servings of seafood/week requires at least some higher fat seafood to be consumed in order for most men and women to meet the AI. Further messages and nutrition resources are needed which provide options on how to increase intake of LC $n-3$ PUFA, specifically through consumption of the higher fat seafood.

Keywords: seafood modelling; older adults; long-chain omega 3 fatty acids; seafood recommendations; Australia

To access the appendices to this article please see Supplementary files under Article Tools online

Received: 28 February 2013; Revised: 9 August 20I3; Accepted: 19 September 20I3; Published: 29 October 2013

T here is widespread literature reporting the health benefits of increased fish and omega 3 consumption on reducing triacylglycerol concentrations (1), and reducing the risk of all-cause mortality (2) and death from cardiac events (3). In particular, as part of a healthy diet, increased fish consumption has been advised to reduce risk for cardiovascular disease (CVD) $(4,5)$. Risk of CVD increases with age, and although there has been a steady decline in its prevalence over the last
30 years, it is still one of the biggest causes of mortality and it contributes a large burden of illness and disability globally (6).

For intake of long-chain omega 3 fatty acids ( $\mathrm{LC} n-3$ PUFA), the National Health and Medical Research Council (NHMRC) in Australia recommends $160 \mathrm{mg} / \mathrm{d}$ for men and $90 \mathrm{mg} / \mathrm{d}$ for women as the Adequate Intake (AI) (7). This is based on observed or experimentallydetermined approximations or estimates of nutrient intake 
for apparently healthy people (7). The NHMRC also recommends a Suggested Dietary Target (SDT) of 610 $\mathrm{mg} / \mathrm{d}$ and $430 \mathrm{mg} / \mathrm{d}$ for adult men and women, respectively; this level of intake may help in prevention of chronic disease (7). Moreover, the Heart Foundation (HF) of Australia also recommends an intake of $500 \mathrm{mg} / \mathrm{d}$ of combined eicosapentanoic acid (EPA) and docosahexanoic acid (DHA) to lower risk of coronary heart disease (4). Thus, there is a range of recommended intakes depending on the health of the individual. These intakes are within the range of values recommended in the Netherlands (8), USA and Canada (9), and France (10).

Regarding the consumption of fish, numerous agencies recommend 2-3 servings of oily fish per week to reduce risk for heart disease $(4,5,9)$ and the World Health Organization recommends regular fish consumption of 1-2 servings/week; each serving should provide the equivalent of 200-500 mg EPA+DHA (11). Compared to recommendations, dietary intakes of seafood and LC $n-3$ PUFA in older Australians as well as older adults overseas (12-15) are inadequate. Only two large dietary surveys conducted in Australia have assessed seafood and/or LC n-3 PUFA consumption $(16,17)$. Among the 45-64 year olds participating in the 1995 National Nutrition Survey (NNS) $(n=4,329)$, mean consumption of fish and seafood products was estimated to be $32.8 \mathrm{~g} / \mathrm{d}$ and in those $\geq 65$ years was $25.6 \mathrm{~g} / \mathrm{d}$; consumption of finfish (excluding canned fish) was just over $8 \mathrm{~g} / \mathrm{d}$ for both age groups (17). In the 2007 Australian National Children's Nutrition and Physical Activity Survey $(n=$ $4,487)$, mean consumption of fish and seafood products was $10-13 \mathrm{~g} / \mathrm{d}$ in boys and $11-15 \mathrm{~g} / \mathrm{d}$ in girls (16). In comparison, a smaller, but recent national survey of 854 Australian adults $\geq 51$ years, identified that $34 \%$ ate finfish and/or seafood $\geq 2$ times/week, with a mean intake of total finfish/seafood of $43 \mathrm{~g} / \mathrm{d}$ and a mean intake of LC $n-3$ PUFA of $508 \mathrm{mg} / \mathrm{d}$ (18). In this group, the most frequently consumed types of finfish ( $\geq 2$ times/ week) were salmon and tuna; however, only $28 \%$ of respondents $(n=242)$ consumed $\geq 500 \mathrm{mg} / \mathrm{d}$ LC $n-3$ PUFA from finfish and/or seafood alone (18). In that same survey, it was found that only $12 \%$ of the older adults consumed higher fat fish $\geq 2$ times/week (e.g. salmon, sardines, herring), whereas $22 \%$ consumed the lower fat fish types $\geq 2$ times/week (e.g. canned tuna, shark and prawns) (18). Moreover, $60 \%$ of the participants identified sardines as being high in oils/fatty acids but only $18 \%$ indicated that salmon and trout were high in oils/fatty acids (19). The perception of what types of seafood contain high amounts of omega 3 likely coincides with the greater percentage of adults consuming the lower fat seafood and the small percentage of adults meeting the recommendations for seafood consumption. Enabling consumers to have an understanding of the potential for specific seafood species to assist in meeting LC $n-3$
PUFA recommendations would be valuable in order to assist in increasing the number of adults achieving health benefits through the consumption of seafood.

In Australia, there is a lack of nutrient composition data for various seafood species $(20,21)$, which makes it difficult to determine the exact amount of LC $n-3$ PUFA consumed. Based on recently completed nutrient profiling of 24 Australian seafood groups (22), it was considered important to identify whether consumption of these different seafood types would provide sufficient LC n-3 PUFA to meet current dietary recommendations. Therefore, the objectives of this study were: (1) to utilise recent nutrient composition data for Australian seafood to determine whether including these types of seafood into a diet based on the Australian Guide to Healthy Eating (AGHE) will achieve LC $n-3$ PUFA recommendations (i.e. AI, SDT, $500 \mathrm{mg} / \mathrm{d} \mathrm{HF}$ recommendation) and (2) to determine the weekly number of lower fat and higher fat servings of seafood required to meet LC $n-3$ PUFA recommendations. Dietary modelling provides information on how combinations of various foods with nutrient composition data can meet nutrient recommendations. Results from the current dietary modelling can inform health professionals on appropriate recommendations for fish consumption (species and frequency of consumption) and how these targets can be achieved.

\section{Methods}

\section{Overview of approach}

Four theoretical dietary modelling procedures were undertaken utilising the nutrient profiling data. Two models involved the incorporation of seafood into a 14-day meal plan consistent with the number of food group servings in the AGHE available for $60+$ year olds (Table 1) (23). The older age group was chosen due to the frequent low intake of seafood $(12-15,18)$ and their higher prevalence of heart disease (6). Theoretical energy and macronutrient intakes from these diets were compared against current Nutrient Reference Values (NRVs) for 51-70 year olds (7). Two further models were carried out to identify the number of weekly servings of lower fat and higher fat seafood required to meet LC $n-3$ PUFA recommendations.

\section{AGHE and nutrient recommendations}

The AGHE was used to build the 14-day menu based on food group guidelines for $60+$ year olds. The AGHE was developed in 1998 and the meal plan was devised so that the different gender and age groups could meet $70 \%$ of the Recommended Daily Intake (RDI) (i.e. RDIs established in 1990). As new NRVs have since been made (7), the current study used the AGHE as the basis for a 14-day meal plan; however, assessment of the theoretical diet was assessed against current NRVs for men and women aged 51-70 years. Specifically, macronutrient 
Table 1. Number of food group servings from the Australian Guide to Healthy Eating for those aged 60 years and over

\begin{tabular}{llcccccc}
\hline & & Breads and cereals $^{\mathrm{a}}$ & Vegetable $^{\mathrm{b}}$ & Fruit $^{\mathrm{c}}$ & Dairy $^{\mathrm{d}}$ & Meat and alternatives $^{\mathrm{e}}$ Extras $^{\mathrm{f}}$ \\
\hline \multirow{3}{*}{ Men } & AGHE & $4-6$ & $4-7$ & $2-3$ & $2-3$ & $1-1.5$ & $0-2.5$ \\
\multirow{3}{*}{ Women } & Dietary modelling & 5.9 & 6.1 & 2.4 & 2.5 & 1.5 & 2.5 \\
& AGHE & $3-5$ & $4-6$ & $2-3$ & $2-3$ & $1-1.5$ & $0-2$ \\
& Dietary modelling & 4.5 & 5.0 & 2.0 & 3.1 & 1.5 & 2.0 \\
\hline
\end{tabular}

Serving size equivalents: ${ }^{\mathrm{a}} 30 \mathrm{~g}$ crackers; I slice bread (40 g); $30 \mathrm{~g}$ cereal; $90 \mathrm{~g}$ dry weight rice/pasta; ${ }^{\mathrm{b}} 75 \mathrm{~g}$ all vegetables; ${ }^{\mathrm{c}} \mathrm{I} 50 \mathrm{~g}$ medium-piece fresh fruit; $125 \mathrm{ml}$ juice; $150 \mathrm{~g}$ diced/canned fruit ${ }^{\mathrm{d}} 250 \mathrm{ml}$ milk; $200 \mathrm{~g}$ yoghurt; $40 \mathrm{~g}$ cheese; ${ }^{\mathrm{e}} \mathrm{I} 00 \mathrm{~g}$ cooked meat, poultry, fish; $75 \mathrm{~g}$ cooked peas; beans, lentils, I/3 cup nuts; I/4 cup seeds; $20 \mathrm{~g}$ oil; I serve $\sim 600 \mathrm{~kJ}$.

recommendations were based on the Acceptable Macronutrient Distribution (AMDR) for protein, carbohydrates, and fat and/or AI for fibre and LC $n-3$ PUFA (160 mg/d men, $90 \mathrm{mg} / \mathrm{d}$ women) (7). The SDT (SDT: 430 $\mathrm{mg} / \mathrm{d}$ women, $610 \mathrm{mg} / \mathrm{d}$ men) (7) and the HF recommendation of $500 \mathrm{mg} / \mathrm{d} \mathrm{EPA}+\mathrm{DHA}$ (4) were also used in determining the percentage of adults who would meet these LC n-3 PUFA targets.

\section{Food groups and foods}

Commonly consumed foods $(n=207)$ were chosen from the AUSNUT database and their energy and nutrient content was extracted using Food Works (FoodWorks 2009, version 6.0.2539, Xyris Software Brisbane). Twentysix foods were included in the breads and cereals group, in which 11 were white/plain/refined options, 12 were wholegrain/wholemeal options and 3 were classed as 'other' (e.g. fruit bread, crackers). The number of individual foods in the breads and cereals food group was based on the percentage that these foods were consumed by adults $>19$ years from the 1995 NNS. For example, 'bread and bread rolls' provided approximately $40 \%$ of mean daily intake for breads and cereals in that survey (17). Therefore, 8 choices of bread and bread rolls were included in the breads and cereals category. For the 40 vegetable options, 11 were starchy vegetables (potato and sweet corn), 7 were orange/red vegetables (carrot, pumpkin and sweet potato), 5 were darker green and brassica vegetables (broccoli, spinach, green bean, cauliflower and cabbage), and 17 were other types of vegetables (celery, cucumber, lettuce, mushroom, onion, beetroot, capsicum, squash, tomato, broad bean, snow pea, parsnip and zucchini). For the 22 fruit options, 16 were fresh (4 were apples and pears), 3 options were fruit juices, and 3 were canned varieties. Within the 26 dairy options, 11 were various milk types (e.g. skim, low fat, full fat), 8 were cheese, 4 were yoghurt and 3 were other (custard, ice cream, condensed milk). For the meat and alternative options, 14 were red meat (including veal and pork), 6 white meat (chicken and turkey), 7 beans/legumes, 3 options for eggs, and 7 options for nuts and seeds. Sausages, bacon, salamitype deli meats were included in the extras category due to their higher energy, fat, and sodium content, even though they were reported in the NNS under the meat and meat dishes group. An option of ice cream was included in the dairy and extras category as it contains calcium, but also can be high in fat/sugar. There were 58 options for the extras category in which the majority contained approximately $600 \mathrm{~kJ} /$ serving (e.g. $400 \mathrm{ml}$ regular beer, $596 \mathrm{~kJ} ; 40 \mathrm{~g}$ iced apple cake, $607 \mathrm{~kJ}$; $40 \mathrm{~g}$ pure cream, $664 \mathrm{~kJ}$; $60 \mathrm{~g}$ party sausage roll, $799 \mathrm{~kJ}$ ), as well as 6 options of unsaturated fats and oil foods ( 3 margarine, 3 oils).

\section{Nutrient profiles of seafood}

Twenty-one different seafood species sampled between July 2010 and July 2011, from the 2012 Australian Seafood Compositional Profiles study (22) were included in the models (including both wild and farmed seafood for 3 of the species, totalling 24 different groups of seafood). In the profiles study, most seafood products were analysed raw (except burrowing black fish and the farmed prawn species) and all values were reported in $100 \mathrm{~g}$ portions (Table 2). Due to changes in food weight upon cooking, a weight change factor for the raw products was used (24). Weight change factors (reported as a percentage) were listed for 'finfish, fresh, frozen' that had either been baked ( $-24 \%$ weight change), grilled $(-26 \%)$, microwaved $(-19 \%)$, poached $(-16 \%)$ and steamed $(-17 \%)$. A weight change factor of $-25 \%$ (i.e. $100 \mathrm{~g}$ fish $-25 \%$ loss $=75$ for calculation) was used as an intermediate between baked and grilled weight loss as this was the most frequently reported method of cooking in a previous study that we conducted (18). In addition, to account for any changes in fatty acid content following weight loss during cooking, a retention factor was used to convert fatty acid content of raw fish to fatty acid content in cooked fish $(0.8$ for fish with $>5 \%$ fat content, 0.95 for fish with $<5 \%$ fat content and 1.0 for crustaceans and molluscs). It was assumed that the change in any particular fatty acid content would be similar to the changes in total fat content upon cooking. As there are no current data on retention factors for fatty acids, values were adopted from retention factors reported in a 
Table 2. Seafood species, long-chain omega 3 content (per $100 \mathrm{~g}$ ) and frequencies used in the dietary modelling

\begin{tabular}{|c|c|c|c|c|c|c|}
\hline Seafood species & Aquaculture/wild & EPA (mg) & $\mathrm{DHA}(\mathrm{mg})$ & DPA (mg) & Frequencies of selection (Model I) & Frequencies of selection (Model 2) \\
\hline Atlantic Salmon & Aquaculture & 1,030 & 790 & 372 & 0.142 & - \\
\hline Australian Sardine & Wild & 450 & 178 & 21.8 & 0.014 & 0.022 \\
\hline Banana Prawn* & Aquaculture & 130 & 83.8 & 6.25 & 0.014 & 0.022 \\
\hline Banana Prawn & Wild & 63.4 & 76.7 & 10.7 & 0.014 & 0.022 \\
\hline Barramundi & Aquaculture & 370 & 401 & 133 & 0.057 & 0.088 \\
\hline Black Lip Abalone & Wild & 1.25 & 37.2 & 52.2 & 0.003 & 0.004 \\
\hline Black Lip Abalone & Aquaculture & 18 & 65.2 & 68.5 & 0.003 & 0.004 \\
\hline Black Tiger Prawn* & Aquaculture & 116 & 110 & 6.4 & 0.014 & 0.022 \\
\hline Blue Sprat & Wild & 269 & 95.8 & 17.2 & 0.003 & 0.004 \\
\hline Brown Lip Abalone & Wild & 0.5 & 27.5 & 45.5 & 0.003 & 0.004 \\
\hline Brown Tiger Prawn & Wild & 125 & 126 & 13.7 & 0.014 & 0.022 \\
\hline Burrowing Blackfish* & Wild & 1.2 & 10 & 0.1 & 0.003 & 0.004 \\
\hline Endeavour Prawn & Wild & 69.6 & 81.9 & 9.9 & 0.014 & 0.022 \\
\hline Green Lip Abalone & Wild & 0.25 & 23.2 & 44.8 & 0.003 & 0.004 \\
\hline Green Lip Abalone & Aquaculture & 12.5 & 40.3 & 41.7 & 0.003 & 0.004 \\
\hline Gummy Shark & Wild & 112 & 19.3 & 9.1 & 0.071 & 0.110 \\
\hline Native Oyster & Aquaculture & 201 & 143 & 17.3 & 0.009 & 0.015 \\
\hline Ocean Trout & Aquaculture & 1,910 & 1,190 & 420 & 0.142 & - \\
\hline Pacific Oyster & Aquaculture & 313 & 274 & 23 & 0.009 & 0.015 \\
\hline School Prawn & Wild & 82.6 & 116 & 12.9 & 0.014 & 0.022 \\
\hline Southern Rock Lobster & Wild & 51.8 & 93 & 10.1 & 0.014 & 0.022 \\
\hline Sydney Rock Oyster & Aquaculture & 394 & 304 & 41.5 & 0.009 & 0.015 \\
\hline Western King Prawn & Wild & 102 & 118 & 16.2 & 0.014 & 0.022 \\
\hline Yellowtail Kingfish & Aquaculture & 873 & 994 & 275 & 0.071 & - \\
\hline Tuna, canned in brine ${ }^{\dagger}$ & Not reported & 45 & 303 & 10 & 0.227 & 0.352 \\
\hline Tuna, yellowfin steaks grilled or bbq, brushed with olive oil ${ }^{\dagger}$ & Not reported & 52 & 252 & 18 & 0.114 & 0.176 \\
\hline
\end{tabular}

*Products were analysed cooked.

Values taken from NUTTAB 2010 
German publication (25). The content of LC $n-3$ PUFA ranged from $11.3 \mathrm{mg} / 100 \mathrm{~g}$ (cooked burrowing blackfish) to $3,755 \mathrm{mg} / 100 \mathrm{~g}$ (cooked ocean trout). Three of the species were considered to be high fat ('higher fat', $\geq 10 \%$ total fat: Atlantic salmon, ocean trout, yellowtail kingfish), according to the HF in Australia (26), one was moderate in total fat (barramundi, 7.4\%) and the remaining were considered to be low fat ( $<5 \%$ total fat). The moderate-fat and low-fat seafood species were grouped ('lower fat').

\section{Theoretical dietary modelling: risk solver}

The Risk Solver programme is an add-on feature to the Microsoft Excel computer programme (Risk Solver Premium V9.0.4.0 program; Frontline Systems, Inc.). The programme allows the random selection of foods from a list of pre-determined foods in which energy and nutrient profiles can be assessed. Diet simulation models were based on AGHE food group recommendations, and the food groups (iterations) that were included were usual food items consumed with percentage consumption frequencies based on the 1995 NNS (17). Seafood consumption frequencies were based on a recent Australian survey (18) that involved a similar age group to what the current theoretical models were performed against. Running the simulation procedure randomly selects each single food item according to the imputed number of daily serves in each food group (e.g. 5 random bread/cereal items from the list of 26, 2 random fruit items from the list of 22 fruits). This results in a mean intake of energy and nutrients for the whole day and for each food group. Based on a 14-day menu (varying in the number of serves for each food group/d and to reach overall AGHE recommendations), the simulation process runs the varying combinations 10,000 times (e.g. 10,000 combinations of 5 items of breads and cereals from the 26-item category) and mean energy and nutrient intakes are produced for each day and for the 14-day period. The likelihood (\%) in which the theoretical diet would meet nutrient recommendations for a particular gender and/ or age group can be calculated using estimated means calculated from the 14-day model.

\section{Model I}

The aim of Model 1 was to determine whether a simulation model which included a random selection of seafood types will meet the AI, SDT, and HF recommendation for LC $n-3$ PUFA in men and women 51-70 years of age, as well as the AMDR for protein, fat and carbohydrate, and AI for fibre. Consumption of seafood was entered at an average of 0.3 servings/d for women and 0.4 servings/d for men; over 1 week this reaches the recommendation of 2-3 servings (4). Each type of seafood was assigned a selection probability factor such that the more frequently consumed seafood (e.g. Atlantic salmon) was more likely to be selected than those less frequently consumed (e.g. abalone). Selection probability factors were estimated based on our recent survey (18) and are provided in Supplementary Tables 1-3. Due to the relatively frequent consumption of tuna (18), an option for canned tuna and for grilled/barbequed tuna was also included. The nutrient composition for tuna was taken from the NUTTAB 2010 database; therefore, a total of 26 seafood groups were available for selection in the modelling process. The number of servings for all other food categories was also entered over the 14 days according to AGHE recommendations (e.g. Day 1: 5 servings of breads and cereals, two servings of fruit; Day 2: 4 servings of breads and cereals, 2 servings of extras, etc.).

\section{Model 2}

The aim of Model 2 was to determine whether including a random selection of the lower fat seafood $(<10 \%$ total fat) will achieve LC $n-3$ PUFA recommendations for men and women aged 51-70 years in accordance with the AGHE. The seafood in Model 2 included Australian sardine, barramundi, blue sprat, burrowing blackfish, farmed prawns, wild prawns, gummy shark, oysters, southern rock lobster, and wild abalone, plus the two tuna options. A total of 23 lower fat seafood groups were included in the modelling process.

\section{Model 3 and Model 4}

Two simulation models were undertaken to determine the number of servings of lower fat (Model 3) or higher fat seafood (Model 4) to meet LC n-3 PUFA recommendations from only seafood sources. Each lower or higher fat seafood was randomly included in the model in a continuous fashion until LC $n-3$ PUFA recommendations were met by $100 \%$ of men and women.

\section{Results}

\section{Model I: simulation of all seafood species}

Appropriate numbers of food group servings from the AGHE were entered into a theoretical 14-day menu plan (Table 1), in which the numbers and types of foods from these food groups were randomly selected. The mean intake of energy, macronutrients and LC $n-3$ PUFA, and the percentage of men and women who would meet recommendations when including $0.3-0.4$ servings/d (2-3 servings/week) of higher and lower fat seafood in an AGHE diet are described in Table 3. For women, including 2 servings/week of any type of seafood would result in $89 \%$ meeting the LC $n-3$ PUFA AI, while $66 \%$ of men would meet the AI with 3 servings/week. For both men and women, $37 \%$ would meet their respective SDT. The percentage of men and women that would meet the 
Table 3. Percentage of men and women aged 51-70 years who would meet energy, macronutrient, and long-chain omega 3 requirements from a theoretical 14-day AGHE plan (Model 1)

\begin{tabular}{|c|c|c|c|c|}
\hline & \multicolumn{2}{|c|}{ Men } & \multicolumn{2}{|c|}{ Women } \\
\hline & Mean & $\%$ & Mean & $\%$ \\
\hline Energy (kJ) & 8,190 & $25^{\mathrm{a}}$ & 7,448 & $59^{\mathrm{b}}$ \\
\hline Protein (g) & 93 & $100^{c}$ & 91 & $100^{c}$ \\
\hline $\mathrm{CHO}(\mathrm{g})$ & 246 & $80^{c}$ & 213 & $67^{c}$ \\
\hline Sugar $(g)$ & 109 & - & 103 & - \\
\hline Fat $(g)$ & 58 & $77^{c}$ & 56 & $77^{c}$ \\
\hline Saturated fat (g) & 24 & $40^{c}$ & 24 & $27^{c}$ \\
\hline Polyunsaturated fat (g) & 10 & - & 9 & - \\
\hline Monounsaturated fat (g) & 19 & - & 18 & - \\
\hline Fibre $(\mathrm{g})$ & 31 & $53^{d}$ & 25 & $52^{d}$ \\
\hline Total LC $n-3$ PUFA (mg) & 585 & $66^{\mathrm{d}} ; 37^{\mathrm{e}}$ & 404 & $89^{\mathrm{d}} ; 37^{\mathrm{e}}$ \\
\hline EPA (mg) & 267 & - & 182 & - \\
\hline DHA (mg) & 235 & - & 160 & - \\
\hline DPA (mg) & 83 & - & 62 & - \\
\hline $\mathrm{EPA}+\mathrm{DHA}(\mathrm{mg})$ & 502 & $36^{\mathrm{f}}$ & 342 & $36^{f}$ \\
\hline
\end{tabular}

AGHE: Australian Guide to Healthy Eating; LC $n-3$ PUFA: long-chain omega 3 polyunsaturated fatty acids; EPA: eicosapentanoic acid; DHA: docosahexanoic acid; DPA: docosapentanoic acid.

${ }^{a}$ Energy requirement for an average 51 to 70 -year-old male, $1.7 \mathrm{~m}$ tall and with a physical activity level of 1.4 ; ${ }^{\mathrm{b}}$ Energy requirement for an average 51 to 70 -year-old female, $1.6 \mathrm{~m}$ tall and with a physical activity level of 1.4; 'AMDR: Acceptable Macronutrient Distribution; ${ }^{\mathrm{d}} \mathrm{Al}$ : Adequate Intake: Women: $90 \mathrm{mg} / \mathrm{d}$, Men $160 \mathrm{mg} / \mathrm{d}$; ${ }^{e} \mathrm{SDT}$ : Suggested Dietary Target: Women $430 \mathrm{mg} / \mathrm{d}$, Men $610 \mathrm{mg} / \mathrm{d}$; ${ }^{\mathrm{f}}$ Heart Foundation recommendation in Australia $(500 \mathrm{mg} / \mathrm{d})$.

$\mathrm{HF}$ recommendation of $500 \mathrm{mg} / \mathrm{d}$ of combined EPA+ DHA was $36 \%$.

\section{Model 2: simulation of low-fat seafood into AGHE}

Model 2 describes the mean intake of energy, macronutrients and LC $n-3$ PUFA following random selection of the lower fat seafood, at a frequency of 0.3 servings/d for women ( 2 servings/week) and 0.4 servings/d for men (3 servings/week) (Table 4). Eighty-three percent of women and $47 \%$ of men would achieve the AI for LC $n-3$ PUFA. Only 0.3 and $0.4 \%$ of men and women, respectively, would achieve the SDT and none would achieve the $500 \mathrm{mg} / \mathrm{d}$ HF recommendation.

\section{Model 3 and 4: simulation of low-fat seafood and high-fat seafood}

Random selection of $100 \mathrm{~g}$ servings/week of lower fat seafood would provide approximately $54 \mathrm{mg} / \mathrm{d}$ of LC $n-3$ PUFA (Table 5). For women, 2.5 and 10 servings/week of lower fat seafood would be required for about $90 \%$ to meet the respective LC $n-3$ PUFA AI and SDT. For men, 4 and 14 servings/week of lower fat seafood would
Table 4. Percentage of men and women aged 51-70 years who would meet energy, macronutrient, and long-chain omega 3 requirements from a theoretical 14-day AGHE plan (Model 2).

\begin{tabular}{lrrrrrr}
\hline & \multicolumn{2}{c}{ Men } & & \multicolumn{2}{c}{ Women } \\
\cline { 2 - 3 } \cline { 5 - 6 } & Mean & $\%$ & & Mean & $\%$ \\
\hline Energy (kJ) & 8,080 & $19^{\mathrm{a}}$ & & 7,375 & $54^{\mathrm{b}}$ \\
Protein (g) & 93 & $100^{\mathrm{c}}$ & & 91 & $100^{\mathrm{c}}$ \\
CHO (g) & 246 & $83^{\mathrm{c}}$ & & 213 & $69^{\mathrm{c}}$ \\
Sugar (g) & 109 & - & & 103 & - \\
Fat (g) & 55 & $75^{\mathrm{c}}$ & & 54 & $77^{\mathrm{c}}$ \\
Saturated fat (g) & 23 & $43^{\mathrm{c}}$ & & 24 & $28^{\mathrm{c}}$ \\
Polyunsaturated fat (g) & 9 & - & & 9 & - \\
Monounsaturated fat (g) & 18 & - & & 17 & - \\
Fibre (g) & 31 & $53^{\mathrm{d}}$ & & 25 & $52^{\mathrm{d}}$ \\
Total LC n-3 PUFA (mg) & 194 & $47^{\mathrm{d}} ; 0.3^{\mathrm{e}}$ & & 143 & $83^{\mathrm{d}} ; 0.4^{\mathrm{e}}$ \\
EPA (mg) & 63 & - & & 45 & - \\
DHA (mg) & 106 & - & & 74 & - \\
DPA (mg) & 26 & - & & 23 & - \\
EPA +DHA (mg) & 169 & $0.0 \%^{\mathrm{f}}$ & & 119 & $0.0 \%^{\mathrm{f}}$ \\
\hline
\end{tabular}

AGHE: Australian Guide to Healthy Eating; LC $n-3$ PUFA: long-chain omega 3 polyunsaturated fatty acids; EPA: eicosapentanoic acid; DHA: docosahexanoic acid; DPA: docosapentanoic acid.

${ }^{a}$ Energy requirement for an average $5 \mathrm{I}$ to 70 -year-old male, $1.7 \mathrm{~m}$ tall

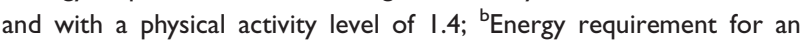
average $5 \mathrm{I}$ to 70 -year-old female, $1.6 \mathrm{~m}$ tall and with a physical activity level of I.4; 'AMDR: Acceptable Macronutrient Distribution; ${ }^{\mathrm{d}} \mathrm{Al}$ : Adequate Intake: Women: 90 mg/d, Men 160 mg/d; ' $S D T$ : Suggested Dietary Target: Women $430 \mathrm{mg} / \mathrm{d}$, Men $610 \mathrm{mg} / \mathrm{d}$; ${ }^{\mathrm{f}}$ Heart Foundation recommendation in Australia $(500 \mathrm{mg} / \mathrm{d})$.

be required for about $90 \%$ to achieve the AI and SDT. In contrast, random selection of $100 \mathrm{~g}$ servings/week of higher fat seafood would provide $399 \mathrm{mg} / \mathrm{d}$ of LC $n-3$ PUFA, such that only 0.5 serving/week of higher fat seafood would be needed for men and women to meet the AI and only 1.5-2 servings/week to meet the SDT. In both men and women, consuming 2 servings/week of higher fat seafood would enable the HF recommendation of $500 \mathrm{mg} / \mathrm{d}$ to be met.

\section{Discussion}

The rationale behind the current dietary modelling was to investigate whether including the appropriate number of servings of seafood into national food consumption guidelines would achieve various recommendations for LC $n-3$ PUFA. We report that with a combination of higher and lower fat seafood at a frequency of 2 servings/week, the AI will be met by $89 \%$ of women and consumption of 3 servings/week will enable $66 \%$ of men to meet the AI. This type of modelling demonstrates that the consumption of a variety of seafood in a total diet based on national guidelines will result in at least two-thirds of older adults meeting the LC $n-3$ PUFA AI. However, when including 
Table 5. Simulation to determine frequency of consumption of lower fat seafood and higher fat seafood to meet LC $n-3$ PUFA recommendations

\begin{tabular}{|c|c|c|c|c|c|c|c|c|c|c|c|c|}
\hline \multirow{3}{*}{$\begin{array}{l}\text { Servings/week } \\
\text { (100 g servings) }\end{array}$} & \multicolumn{6}{|c|}{ Lower fat seafood } & \multicolumn{6}{|c|}{ Higher fat seafood } \\
\hline & \multirow{2}{*}{$\begin{array}{l}\text { Mean LC } n-3 \\
\text { PUFA (mg/d) }\end{array}$} & \multicolumn{2}{|c|}{$\begin{array}{l}\text { Percent achieving } \\
\qquad \mathrm{Al}^{\mathrm{a}}(\%)\end{array}$} & \multicolumn{2}{|c|}{$\begin{array}{l}\text { Percent achieving } \\
\text { SDT }^{\mathrm{b}}(\%)\end{array}$} & \multirow{2}{*}{$\begin{array}{c}\text { Percent achieving } \\
500 \mathrm{mg} / \mathrm{d}^{c}(\%)\end{array}$} & \multirow{2}{*}{$\begin{array}{l}\text { Mean LC } n-3 \\
\text { PUFA (mg/d) }\end{array}$} & \multicolumn{2}{|c|}{$\begin{array}{l}\text { Percent achieving } \\
\qquad \mathrm{Al}^{\mathrm{a}}(\%)\end{array}$} & \multicolumn{2}{|c|}{$\begin{array}{l}\text { Percent achieving } \\
\text { SDT }^{\mathrm{b}}(\%)\end{array}$} & \multirow{2}{*}{$\begin{array}{c}\text { Percent achieving } \\
500 \mathrm{mg} / \mathrm{d}^{c}(\%)\end{array}$} \\
\hline & & Women & Men & Women & Men & & & Women & Men & Women & Men & \\
\hline $1 / 2$ & 27 & 0 & 0 & 0 & 0 & 0 & 200 & 100 & 100 & 0 & 0 & 0 \\
\hline 1 & 54 & 14 & 0 & 0 & 0 & 0 & 399 & 100 & 100 & 56 & 0 & 0 \\
\hline $11 / 2$ & 81 & 35 & 2 & 0 & 0 & 0 & 599 & 100 & 100 & 100 & 26 & 70 \\
\hline 2 & 109 & 61 & 8 & 0 & 0 & 0 & 799 & 100 & 100 & 100 & 100 & 100 \\
\hline $2 \mathrm{I} / 2$ & 136 & 94 & 22 & 0 & 0 & 0 & & & & & & \\
\hline 3 & 163 & 100 & 52 & 0 & 0 & 0 & & & & & & \\
\hline $31 / 2$ & 191 & 100 & 71 & 0 & 0 & 0 & & & & & & \\
\hline 4 & 218 & 100 & 92 & 0 & 0 & 0 & & & & & & \\
\hline $4 \mathrm{I} / 2$ & 246 & 100 & 99 & 0 & 0 & 0 & & & & & & \\
\hline 5 & 273 & 100 & 100 & 1 & 0 & 0 & & & & & & \\
\hline $5 \mathrm{I} / 2$ & 300 & 100 & 100 & 2 & 0 & 0 & & & & & & \\
\hline 6 & 328 & 100 & 100 & 5 & 0 & 0 & & & & & & \\
\hline 7 & 382 & 100 & 100 & 22 & 0 & 1 & & & & & & \\
\hline 8 & 437 & 100 & 100 & 51 & I & 6 & & & & & & \\
\hline 9 & 491 & 100 & 100 & 80 & 5 & 23 & & & & & & \\
\hline 10 & 546 & 100 & 100 & 96 & 19 & 53 & & & & & & \\
\hline II & 600 & 100 & 100 & 100 & 43 & 81 & & & & & & \\
\hline 12 & 655 & 100 & 100 & 100 & 70 & 95 & & & & & & \\
\hline 13 & 710 & 100 & 100 & 100 & 89 & 99 & & & & & & \\
\hline 14 & 764 & 100 & 100 & 100 & 97 & 100 & & & & & & \\
\hline 15 & 818 & 100 & 100 & 100 & 100 & 100 & & & & & & \\
\hline
\end{tabular}

${ }^{a} A$ Al: Adequate Intake: Women: 90 mg/d, Men 160 mg/d; bDT: Suggested Dietary Target: Women 430 mg/d, Men 610 mg/d; ' Heart Foundation recommendation in Australia (500 mg/d EPA+DHA). 
only lower fat seafood into the diet, $83 \%$ of women will meet the AI but only $47 \%$ of men will meet it. Comparatively, 0.5 serving/week $(50 \mathrm{~g})$ of higher fat seafood is required for most men and women to meet the AI. These results suggest that meeting the AI for LC $n-3$ PUFA in women is possible, regardless of seafood choice, but it is likely to be a challenge for men, particularly when only lower fat seafood is preferred. Consumption of higher fat seafood appears a simple strategy to meet the AI for men and women on a regular basis.

Numerous agencies recommend 2-3 servings of oily fish per week to reduce risk for heart disease $(4,5,9)$. The $\mathrm{HF}$ also sets out guidance for adult men and women to achieve the appropriate recommendations of omega 3 fatty acids by consuming various types of fish (4). The guidelines generally include species with higher amounts of LC n-3 PUFA such as fresh salmon, canned salmon and canned sardines in $150 \mathrm{~g}$ servings; however, it also includes varieties such as blue trevalla and gemfish (27). Our modelling demonstrates the potential to include the appropriate number of seafood into a usual weekly diet; however, the further recommendation of the amount of fatty acids to consume (i.e. a target of $500 \mathrm{mg} / \mathrm{d} \mathrm{EPA}+$ DHA) produces a poorer result. This target would only be met by one-third of older adults when choosing a combination of higher and lower fat seafood, and the choice of only lower fat seafood would not enable any older adult to meet this target. In line with the guidelines, consumption of 2 servings of the higher fat seafood would enable $100 \%$ of men and women to meet the $500 \mathrm{mg} / \mathrm{d}$ recommendation. Therefore, for older adults wishing to reduce their risk of $\mathrm{CHD}$, both a mixed seafood diet and a lower seafood diet does not appear to be an appropriate option; yet following the guidance of 2-3 servings of oily seafood per week is sufficient.

The NHMRC defines the SDT as a daily average intake from food and beverages for certain nutrients that may help in prevention of chronic disease (7). In our modelling of lower fat seafood, 14 servings/week and 10 servings/week would be required for men and women, respectively, to achieve the SDT. Comparatively, only 1.5-2 servings/week of higher fat seafood would be required to meet the SDT. This indicates that for individuals at risk of CVD, it would be extremely difficult to meet the SDT when the consumption of lower fat seafood only is desired. Additional strategies such as a fish oil supplement would be advised to meet the SDT.

It is clear from several studies in Australia (18, 20, 28) and overseas $(13,14,29)$ that consumption of seafood is low. In addition, we (18), and others (17), have previously reported that lower fat seafood such as tuna and prawns are consumed in higher frequencies compared to higher fat seafood such as salmon and ocean trout. As a result of our modelling, consumption of lower fat seafood alone poses a problem for both men and women when trying to meet targets relevant to heart disease, and for men when trying to achieve the AI. Moreover, we demonstrated that for $90 \%$ of men to reach the AI from lower fat seafood alone, 4 servings/week would need to be consumed. For $90 \%$ of women to reach the AI, 2.5 servings/week of lower fat seafood would need to be consumed. This may not be feasible for a large proportion of the population on a weekly basis. Furthermore, when including a random selection of higher fat seafood, the percentage of adults who would meet these targets only slightly increased. In contrast, only 0.5 serving/week of higher fat seafood would be required for adults to meet the AI. Problematically, there are a limited variety of higher fat seafood species available on the Australian market (e.g. salmon, ocean trout, sardines, kingfish), thereby reducing choice in their selection. We also recently reported that in a sample of 854 older adults, only 38 and 18\% indicated that salmon and trout were high in oils (fatty acids), respectively (19). Unpublished data from that survey also identified that $44 \%(n=378)$ believed they ate the right amount of finfish/ seafood, $44 \%$ consumed finfish/seafood $\geq 2$ times/week, but only $28 \%$ met the HF recommendation of $500 \mathrm{mg} / \mathrm{d}$ (4). Thus, there appears some disconnect regarding the types of seafood that need to be consumed in order to meet recommendations with what is actually being consumed.

Limitations to this analysis include that the modelling was 'theoretical', as food patterns were based on AGHE recommendations and were not based on typical dietary intakes for this age group. Therefore, the study results are not likely to be generalisable to all adults. However, the most recent nutrient intake data from Australia are the 1995 NNS (17). Results from that survey are outdated and food consumption patterns have changed (30). Dietary intake data from the most recent Australian NNS in 2010 were also not available; and the new Australian Dietary Guidelines were still in the draft form. Therefore, food consumption patterns were based on those most recently available. However, as a comparison to the draft guidelines, the number of servings of food groups from our modelling was not overly different (data not shown). Seafood types included in the study also were not representative of those available to consumers on the market, as compositional profiles were only available for a subset of all seafood, and did not include imported products. Therefore, other varieties of seafood that might also be consumed in Australia were not reflected in this data. However, tuna was included to limit this bias, and other seafood types that are frequently consumed such as barramundi and prawns were included in the analyses. Thus, we did capture a sound profile of seafood that could be included in a menu plan.

Based on the overall dietary modelling, it is evident that certain recommendations are difficult to achieve 
depending on the type of seafood chosen as well as the type of recommendation and reason for it to be achieved. This can clearly create confusion in the community when trying to determine individual targets for LC $n-3$ PUFA intake, or when individuals have a misunderstanding regarding the types of seafood to be consumed in order to meet targets. Altering the types of seafood from those higher in fat to only those lower in fat decreases the percentage of adults who would meet suggested targets. Our modelling provides evidence that consumption of 2-3 servings of higher fat seafood per week will meet any of the recommendations for LC n-3 PUFA intake, and therefore this recommendation appears to be most appropriate to communicate to the public. As previously discussed, many older adults do not recognise which types of seafood are higher in fatty acids, and therefore, in conjunction with the recommendation of 2-3 servings of fatty seafood, it is encouraged that guidance on the types of seafood to be consumed is highlighted. For those continuing to choose lower fat seafood, the option of a fish oil supplement would be required. Further messages and nutrition resources are needed which provide options on how to increase intake of LC $n-3$ PUFA, specifically through consumption of the higher fat seafood. This could be achieved through targeted education programmes, which could help inform a wide range of consumers about the consumption of seafood and meeting LC $n-3$ PUFA requirements.

\section{Conflict of interest and funding}

This work was supported by the Australian Seafood Corporate Research Centre but had no input into the results presented in the current report. No conflict of interest exists for any author.

\section{References}

1. Shearer GC, Savinova OV, Harris WS. Fish oil-how does it reduce plasma triglycerides? Biochim Biophys Acta 2011; 1821: $843-51$.

2. Wang C, Harris WS, Chung M, Lichtenstein AH, Balk EM, Kupelnick B, et al. n-3 Fatty acids from fish or fish-oil supplements, but not alpha-linolenic acid, benefit cardiovascular disease outcomes in primary- and secondary-prevention studies: a systematic review. Am J Clin Nutr 2006; 84: 5-17.

3. Mozaffarian D, Wu JH. Omega-3 fatty acids and cardiovascular disease: effects on risk factors, molecular pathways, and clinical events. J Am Coll Cardiol 2011; 58: 2047-67.

4. Heart Foundation. Position statement. Fish, fish oils, n-3 polyunsaturated fatty acids and cardiovascular health; http://www. heartfoundation.org.au/SiteCollectionDocuments/Fish-positionstatement.pdf; 2008 [cited 22 June 2012].

5. Lichtenstein AH, Appel LJ, Brands M, Carnethon M, Daniels $\mathrm{S}$, Franch HA, et al. Diet and lifestyle recommendations revision 2006: a scientific statement from the American Heart Association Nutrition Committee. Circulation 2006; 114: 82-96.

6. Australian Bureau of Statistics. Cardiovascular disease in Australia: a snapshot, 2004-05. Number 4821.0.55.001; http:// www.abs.gov.au/ausstats/abs@.nsf/mf/4821.0.55.001/; 2004 [cited 16 June 2012].

7. National Health and Medical Research Council. Nutrient reference values for Australia and New Zealand. Department of Health and Ageing; http://www.nhmrc.gov.au/_files_nhmrc/ file/publications/synopses/n35.pdf; 2006 [cited 19 June 2011].

8. Health Council of the Netherlands. Guidelines for a healthy diet 2006. The Hague: Health Council of the Netherlands; publication no. 2006/21E. ISBN 90-5549-656-3; http://www. gezondheidsraad.nl/en/publications/guidelines-healthy-diet-20060; 2006 [cited 16 June 2012]

9. Kris-Etherton PM, Innis S, Ammerican Dietetic Association, Dietitians of Canada. Position of the American Dietetic Association and Dietitians of Canada: dietary fatty acids. J Am Diet Assoc 2007; 107: 1599-611.

10. Martin AE. Apports nutritionnels conseilles pour la population Francaise, 3rd edition. France: Tech. \& Doc Lavoisier; 2001.

11. WHO (2003). Diet, nutrition, and the prevention of chronic diseases. FAO/WHO Technical Report Series. Geneva, Switzerland: World Health Organization.

12. Lopez-Garcia E, Schulze MB, Manson JE, Meigs JB, Albert $\mathrm{CM}$, Rifai N, et al. Consumption of (n-3) fatty acids is related to plasma biomarkers of inflammation and endothelial activation in women. J Nutr 2004; 134: 1806-11.

13. van Woudenbergh GJ, van Ballegooijen AJ, Kuijsten A, Sijbrands EJ, van Rooij FJ, Geleijnse JM, et al. Eating fish and risk of type 2 diabetes: a population-based, prospective follow-up study. Diabetes Care 2009; 32: 2021-6.

14. Virtanen JK, Mozaffarian D, Chiuve SE, Rimm EB. Fish consumption and risk of major chronic disease in men. Am $\mathbf{J}$ Clin Nutr 2008; 88: 1618-25.

15. Welch AA, Bingham SA, Ive J, Friesen MD, Wareham NJ, Riboli E, et al. Dietary fish intake and plasma phospholipid n-3 polyunsaturated fatty acid concentrations in men and women in the European Prospective Investigation into Cancer-Norfolk United Kingdom cohort. Am J Clin Nutr 2006; 84: 1330-9.

16. Department of Health and Ageing (2007). Australian National Children's Nutrition and Physical Activity Survey: main findings report. Prepared by the Commonwealth Scientific Industrial Research Organisation (CSIRO), Preventative Health National Research Flagship, and the University of South Australia. Canberra, ACT; http://www.health.gov.au; 2008 [cited 1 August 2012].

17. McLennan W, Podger A. National Nutrition Survey: foods eaten, 1995. Australia. Australian Bureau of Statistics Catalogue No. 4804.0, Australian Bureau of Statistics, Canberra, 1999.

18. Grieger J, Miller M, Cobiac L. Fish consumption and use of omega 3 supplements in a sample of older Australians. Nutrition and Dietetics 2013; 70: 227-35.

19. Grieger JA, Miller M, Cobiac L. Knowledge and barriers relating to fish consumption in older Australians. Appetite 2012; 59: 456-63.

20. Flood VM, Webb KL, Rochtchina E, Kelly B, Mitchell P. Fatty acid intakes and food sources in a population of older Australians. Asia Pac J Clin Nutr 2007; 16: 322-30.

21. Mann NJ, Sinclair AJ, Percival P, Lewis JL, Meyer BJ, Howe PRC. Development of a database of fatty acids in Australian foods. Nutr Diet 2003; 60: 42-5.

22. Padula D, Kiermeier A, McLeod C. Australian seafood compositional profiles: final report; March 2012 [cited 21 September 2012]. Australian Seafood Cooperative Research Centre.

23. Department of Health and Ageing. Australian Guide to Healthy Eating. http://www.eatforhealth.gov.au/sites/default/files/files/ public_consultation/n55d_draft_dietary_guidelines_agthe_111212. pdf; 2013 [cited 20 February 2013]. 
24. Food Standards Australia New Zealand. Australian food and nutrient database for nutrition labelling-release 3: nutrition panel calculator. Appendix 5: weight change factors; http:// www.foodstandards.gov.au/_srcfiles/Explanatory_notes_for_the NPC_coldfusion_October_2004_fina $\%$ E2 $\% 80 \%$ A6.pdf; 2004 [cited 15 July 2011].

25. Bognar AL. Tables on weight yield of food and retention factors of food constituents for the calculation of nutrient composition of cooked foods (dishes). Berichte der Bundesforschungsanstalt für Ernährung. Karlsruhe. 2002.

26. Heart Foundation. Review of evidence fish, fish oils, n-3 polyunsaturated fatty acids and cardiovascular health. http://www. heartfoundation.org.au/SiteCollectionDocuments/Fish-FishOilsrevie-of-evidence.pdf; 2008 [cited 15 October 2012].

27. Heart Foundation. Omega-3: Q\&A. Eating plans. http:// www.heartfoundation.org.au/SiteCollectionDocuments/Fish-QAGeneral.pdf; 2008 [cited 29 August 2012].
28. Howe P, Meyer B, Record S, Baghurst K. Dietary intake of long-chain omega-3 polyunsaturated fatty acids: contribution of meat sources. Nutrition 2006; 22: 47-53.

29. Bechoua S, Dubois M, Vericel E, Chapuy P, Lagarde M, Prigent AF. Influence of very low dietary intake of marine oil on some functional aspects of immune cells in healthy elderly people. Br J Nutr 2003; 89: 523-31.

30. Flood VM, Burlutsky G, Webb KL, Wang JJ, Smith WT, Mitchell P. Food and nutrient consumption trends in older Australians: a 10-year cohort study. Eur J Clin Nutr 2010; 64: 603-13.

*Jessica A. Grieger

Department of Nutrition and Dietetics

Flinders University

South Australia

Email: jessag00 I@gmail.com 